\title{
Al-Waste-Based Zeolite Adsorbent Used for the Removal of Ammonium from Aqueous Solutions
}

\author{
Ruth Sánchez-Hernández $\mathbb{D D}^{1}{ }^{1}$ Isabel Padilla $\mathbb{D D}^{1},{ }^{1}$ Sol López-Andrés ${ }^{(\mathbb{D})}{ }^{2}$ \\ and Aurora López-Delgado (iD) ${ }^{1}$ \\ ${ }^{1}$ National Centre for Metallurgical Research (CSIC), Madrid 28040, Spain \\ ${ }^{2}$ Department of Mineralogy and Petrology, Faculty of Geology, University Complutense of Madrid, Madrid 28040, Spain
}

Correspondence should be addressed to Aurora López-Delgado; alopezdelgado@cenim.csic.es

Received 26 February 2018; Accepted 8 July 2018; Published 1 August 2018

Academic Editor: Eric Guibal

Copyright (C) 2018 Ruth Sánchez-Hernández et al. This is an open access article distributed under the Creative Commons Attribution License, which permits unrestricted use, distribution, and reproduction in any medium, provided the original work is properly cited.

\begin{abstract}
This work evaluates the use of a synthetic $\mathrm{NaP} 1$ zeolite obtained from a hazardous Al-containing waste for the removal of ammonium $\left(\mathrm{NH}_{4}^{+}\right)$from aqueous solutions by batch experiments. Experimental parameters, such as $\mathrm{pH}$ (6-8), contact time (1-360 min), adsorbent dose $(1-15 \mathrm{~g} / \mathrm{L})$, and initial $\mathrm{NH}_{4}{ }^{+}$concentration $(10-1500 \mathrm{mg} / \mathrm{L})$, were evaluated. Adsorption kinetic models and equilibrium isotherms were determined by using nonlinear regression. The kinetic was studied by applying both the pseudo-firstorder and pseudo-second-order models. The equilibrium isotherms were analyzed according to two-parameter equations (Freundlich, Langmuir, and Temkin) and three-parameter equations (Redlich-Peterson, Sips, and Toth). The results showed that the $\mathrm{NH}_{4}{ }^{+}$uptake on $\mathrm{NaP} 1$ was fast $(15 \mathrm{~min})$ leading to a high experimental sorption capacity $(37.9 \mathrm{mg} / \mathrm{g})$. The $\mathrm{NH}_{4}{ }^{+}$removal on NaP1 was a favorable process that followed the pseudo-first-order kinetic model. The $\mathrm{NH}_{4}{ }^{+}$adsorption was better described by the Sips $(54.2 \mathrm{mg} / \mathrm{g})$ and Toth $(58.5 \mathrm{mg} / \mathrm{g})$ models. NaP1 zeolite from Al-waste showed good $\mathrm{NH}_{4}{ }^{+}$sorption properties, becoming a potential adsorbent to be used in the treatment of contaminated aqueous effluents. Thus, a synergic effect on the environmental protection can be achieved: the end of waste condition of a hazardous waste and the water decontamination.
\end{abstract}

\section{Introduction}

Global industrial development linked to the population growth is promoting the pollution of natural resources, in particular, aquatic environment. Surface and ground waters present significant amounts of harmful substances for human health and environment. Among such substances, excess nitrogen compounds like ammonium $\left(\mathrm{NH}_{4}{ }^{+}\right)$can cause eutrophication depriving of oxygen to aquatic organisms in lakes and rivers. In addition, the $\mathrm{NH}_{4}{ }^{+}$ionized form moves much more slowly than other nitrogen compounds, thus persisting in groundwater for long periods of time after it enters the subsurface [1]. Diverse anthropogenic activities, more specifically, fossil-fuel combustion, septic systems, sewage sludge, landfill leachate, and agricultural practices (including chemical fertilizers or animal manures), lead to an increase in the amount of ammonium in waters [2-4]. Ammonium is also one of the soluble nitrogen species found in airborne particulate matter in urban areas, representing up to approximately $23 \%$ [5]. The Spanish legislation ( $\mathrm{RD} 817 / 2015)$ on the quality of water establishes concentrations of ammonium ranged between 0.2 and $1 \mathrm{mg} / \mathrm{L}$ as acceptable limits. However, higher ammonium concentrations can be found in surface waters, generally, exceeding the limits established by water quality standards [6]. Therefore, the development and improvement of more effective sorbents and water treatment processes to remove contaminants is of vital environmental importance. Biological treatment processes are commonly employed in wastewater treatment facilities. However, several water treatment techniques can be necessary to reduce the content of contaminants in water. Thus, adsorption is a relatively feasible and simple technology that contributes to the elimination of a wide range of substances in aquatic environment. Activated carbons are commonly used as sorbents for the uptake of different compounds from waters. However, such 
materials must be previously treated by activation methods that usually imply high operating temperatures to enhance their porosity and specific surface area [7]. During the last two decades, other potential sorbents like zeolites, that is, porous crystalline materials, have been also used for removal of diverse contaminants [8]. Structurally, both natural and synthetic zeolites are characterized by frameworks built from tetrahedral $\mathrm{TO}_{4}$ primary units (mainly, $\mathrm{T}=\mathrm{Si}$ and $\mathrm{Al}$ ) connected through their oxygen atoms in different ways, resulting in a variety of structures that contain cages, channels, and cavities. The isomorphous substitution of $\mathrm{Si}^{4+}$ by $\mathrm{Al}^{3+}$ in the tetrahedral units leads to formation of negatively charged zeolitic structures that are balanced by the introduction of extra-framework cations (e.g., $\mathrm{Na}^{+}, \mathrm{K}^{+}$, and $\mathrm{Ca}^{2+}$ ). Zeolites, known as molecular sieves and ion exchangers, can be employed as low-cost sorbents compared with activated carbons. Although some zeolites have low specific surface areas as a consequence of their mesoporous character $[9,10]$, it has been found that the ammonium sorption may be related to the sorbent CEC [11]. So, it is likely that one of the most important properties for the elimination of some compounds from water is the CEC. Unlike activated carbons, some zeolites can be used directly in water treatment applications without any previous activation process. Clinoptilolite, a natural zeolite with a CEC ranged between 0.6 and $2.3 \mathrm{meq} / \mathrm{g}$ [12], is widely used due to its good selectivity to ammonium [13-15]. Among synthetic zeolites, $\mathrm{NaP} 1$ is also utilized in water treatment applications [16] due to its 3-dimensional channels with pore sizes ranged between $4.5 \times 3.1$ and $4.8 \times 2.8 \AA$ (according to the International Zeolite Association). Recently, NaP1-type zeolite was synthesized from Al-containing solid wastes leading to a promising sorption capacity $(2.4 \mathrm{meq} / \mathrm{g})$ [10], which is quite similar to commercial Na-type zeolite $(2.7 \mathrm{meq} / \mathrm{g})$ from chemical reagents by Spanish manufacturers. The recovery processes of such Al-waste, included in the European Waste Catalogue (code 1003 21), represented around 12-63\% in Spain during the period 2010-2015, according to the Spanish Register of Emissions and Pollutant Sources. This Al-waste is usually deposited in secure deposits due to its environmental hazards. The synthesis of $\mathrm{NaP} 1$ from a hazardous Al-waste was performed by an eco-friendly bench-scale hydrothermal process [17], contributing to reduce the consumption of raw materials (i.e., water and $\mathrm{NaOH}$ ) and environmental impact. Although both natural zeolites and zeolites from fly ash have been widely used to remove ammonium from waters $[13,14,18,19]$, studies conduced for zeolites from highly Alenriched wastes have not been reported, to our knowledge, in the literature.

Thus, this work attempts to evaluate the removal of $\mathrm{NH}_{4}{ }^{+}$ cation from aqueous solutions onto $\mathrm{NaP} 1$ synthesized from a hazardous Al-waste. The effect of experimental parameters, such as $\mathrm{pH}$, contact time, adsorbent dose, and initial $\mathrm{NH}_{4}{ }^{+}$ concentration, on the removal efficiency and adsorption capacity of Al-waste- $\mathrm{NaP} 1$ was studied by batch tests. In order to better study the uptake process of the adsorbate $\left(\mathrm{NH}_{4}{ }^{+}\right)$by the adsorbent (Al-waste-NaP1), adsorption kinetic and equilibrium isotherms were also evaluated by applying several nonlinear models and error functions.

\section{Materials and Methods}

2.1. Adsorbent and Adsorbate. The adsorbent used in this work was a Na-type zeolite, $\mathrm{NaP} 1$, whose theoretical formula is $\mathrm{Na}_{6} \mathrm{Al}_{6} \mathrm{Si}_{10} \mathrm{O}_{32} \cdot 12 \mathrm{H}_{2} \mathrm{O}$. It was synthesized from a hazardous aluminum waste that is generated from slag milling processes within aluminum industries. The preparation of the zeolite from this Al-waste was developed by a benchscale hydrothermal synthesis process at $120^{\circ} \mathrm{C}$ for $6 \mathrm{~h}$ according to [17]. The evaluation of the main mineralogical and morphological properties of the zeolite was analyzed using X-ray diffraction (XRD) and scanning electron microscope (SEM) as shown in Figure 1. Al-waste-NaP1 was characterized by gismondine-type zeolite showing a tetragonal structure. The zeolite presents a high CEC $(2.4 \mathrm{meq} / \mathrm{g})$ but a low $S_{\text {BET }}\left(15.93 \mathrm{~m}^{2} / \mathrm{g}\right)$ that was quite similar to the $S_{\text {EXT }}$ $\left(15.08 \mathrm{~m}^{2} / \mathrm{g}\right)$ due to its mesoporous character, its $\mathrm{N}_{2}$ adsorption/desorption isotherm, and pore size distribution (as shown in Figure 2(a)). The total pore volume estimated at the relative pressure of 0.99 was $0.04828 \mathrm{~cm}^{3} / \mathrm{g}$. The mesopore and micropore volumes were 0.04785 and $0.00044 \mathrm{~cm}^{3} / \mathrm{g}$, respectively, and the average pore diameter of the zeolite, estimated assuming cylindrical pore shape, was $12.12 \mathrm{~nm}$. The zeta potential ( $\zeta$-potential) of Al-waste$\mathrm{NaP} 1$ indicated that its surface is negatively charged within a wide $\mathrm{pH}$ range (Figure 2(b)); accordingly, the as-obtained zeolite may be considered as a good candidate for sorption of cations like ammonium in waters.

Aqueous solutions containing the adsorbate $\left(\mathrm{NH}_{4}{ }^{+}\right)$ were prepared by dissolving a certain amount of a $1000 \mathrm{mg} / \mathrm{L}$ stock solution of ammonium chloride (Panreac) in deionized water (resistivity $\sim 18.2 \mathrm{M} \Omega \cdot \mathrm{cm}$ ).

2.2. Adsorption Procedure. Adsorption experiments of $\mathrm{NH}_{4}{ }^{+}$on $\mathrm{NaP} 1$ were performed by the batch process under ambient conditions $\left(28 \pm 2^{\circ} \mathrm{C}\right)$ using adsorbate aqueous solutions with a fixed volume $(100 \mathrm{~mL})$. The adsorption ability of $\mathrm{NaP} 1$ was only studied under ambient conditions since the increase of temperature can lead to the decrease of the $\mathrm{NH}_{4}{ }^{+}$adsorption capacity [20]. Before adsorption, blank tests were prepared in order to discard possible contamination resulting from the adsorbent, the reagents or the equipment used during sample processing including filtration. All samples were placed in $150 \mathrm{~mL}$ glass conical flaks which were kept covered and stirred at constant speed (125 rpm) using an orbital and horizontal shaker (Selecta, Rotabit) with speed and time control. The solution $\mathrm{pH}$ was maintained constant during each adsorption experiment by adding small volumes of dilute $\mathrm{NaOH}$ or $\mathrm{HCl}$ aqueous solutions. Thus, the effect of $\mathrm{pH}$, contact time, and adsorbent dose on the ammonium removal efficiency and adsorption capacity was studied using fixed initial concentrations $(50 \mathrm{mg} / \mathrm{L})$. The influence of initial concentration on the $\mathrm{NH}_{4}{ }^{+}$uptake by $\mathrm{NaP} 1$ was evaluated in a wide initial concentration range $(10-1500 \mathrm{mg} / \mathrm{L})$.

2.2.1. Effect of $p H$. The influence of $\mathrm{pH}$ on the ammonium uptake was studied as it influences the ionization of surface 


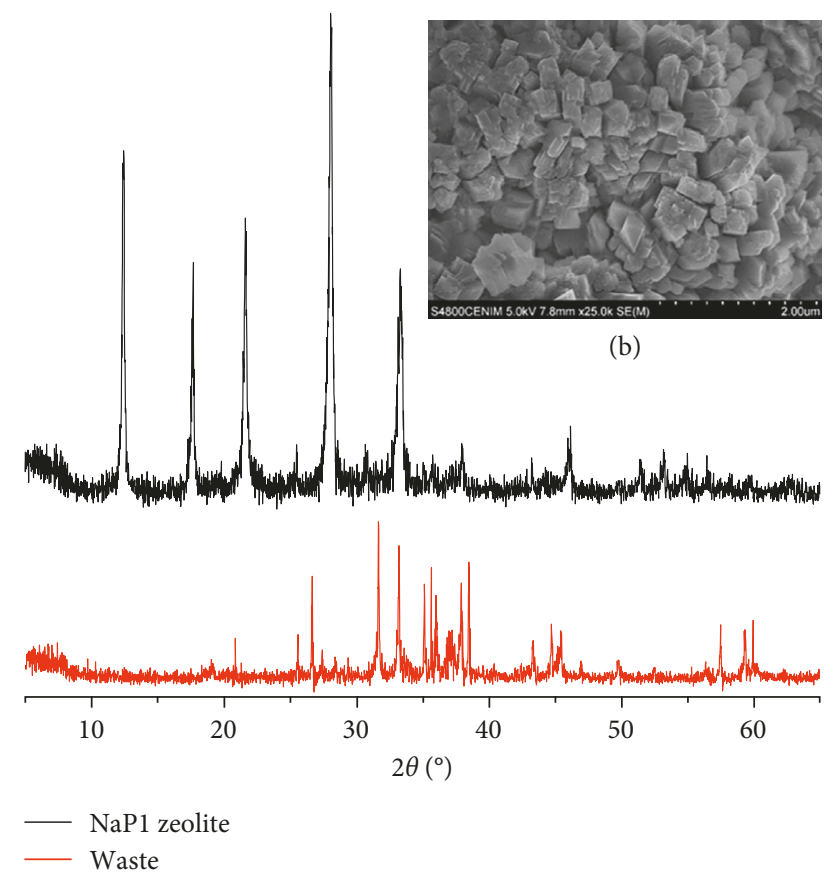

(a)

Figure 1: (a) X-ray diffraction patterns of Al-waste and Al-wasteNaP1. (b) Morphology of Al-waste-NaP1.

groups of the adsorbent and the speciation of different ions present in the adsorption system. Thus, the effect of the $\mathrm{pH}$ on the $\mathrm{NH}_{4}{ }^{+}$cation adsorption by $\mathrm{NaP} 1$ was evaluated at $\mathrm{pH}$ ranged between 6 and 8 , simulating $\mathrm{pH}$ conditions similar to leachates from landfills, which contain high concentrations of ammonium [3]. For the $\mathrm{pH}$ experiments, an adsorbent dose of $5 \mathrm{~g} / \mathrm{L}$ (i.e., $0.5 \mathrm{~g}$ of zeolite per $100 \mathrm{~mL}$ of $\mathrm{NH}_{4}{ }^{+}$ aqueous solution) and an initial adsorbate concentration of $50 \mathrm{mg} / \mathrm{L}$ were selected for a fixed contact time (15 min).

2.2.2. Effect of Contact Time. Before developing equilibrium experiments, the required contact time for reaching the adsorption equilibrium was determined. Thus, the effect of the contact time on the $\mathrm{NH}_{4}{ }^{+}$adsorption efficiency of $\mathrm{NaP} 1$ was studied by varying the time $(1,2,5,10,15,30,60,120$, and $360 \mathrm{~min}$ ) and using $0.5 \mathrm{~g}$ of zeolite per $100 \mathrm{~mL}$ of adsorbate aqueous solution with an initial $\mathrm{NH}_{4}{ }^{+}$concentration of $50 \mathrm{mg} / \mathrm{L}$ at $\mathrm{pH}$ 7.5. The adsorption kinetic on the cation adsorption capacity was also studied by evaluating the pseudo-first-order and pseudo-second-order adsorption rate models. Subsequent adsorption tests were developed according to the optimized parameters.

2.2.3. Effect of Adsorbent Dose. Once selected the optimal conditions of $\mathrm{pH}$ and contact time for the $\mathrm{NH}_{4}{ }^{+}$removal on $\mathrm{NaP} 1$, the adsorbent dose was evaluated by varying the zeolite mass $(0.1,0.25,0.5,0.75,1,1.25$, and $1.5 \mathrm{~g})$ in contact with $100 \mathrm{~mL}$ aqueous solutions of $\mathrm{NH}_{4}{ }^{+}$, with an initial adsorbate concentration of $50 \mathrm{mg} / \mathrm{L}$, at $\mathrm{pH} 7.5$ for the selected equilibrium time (15 $\mathrm{min})$.

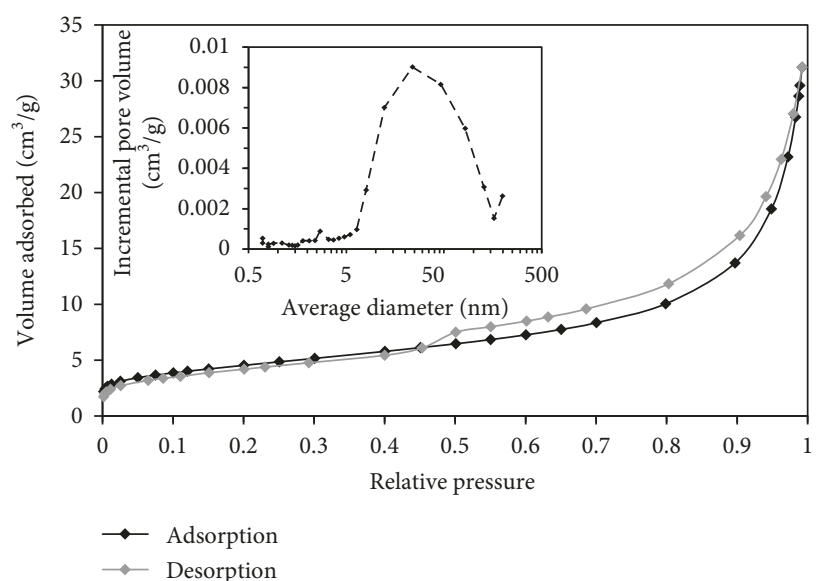

(a)

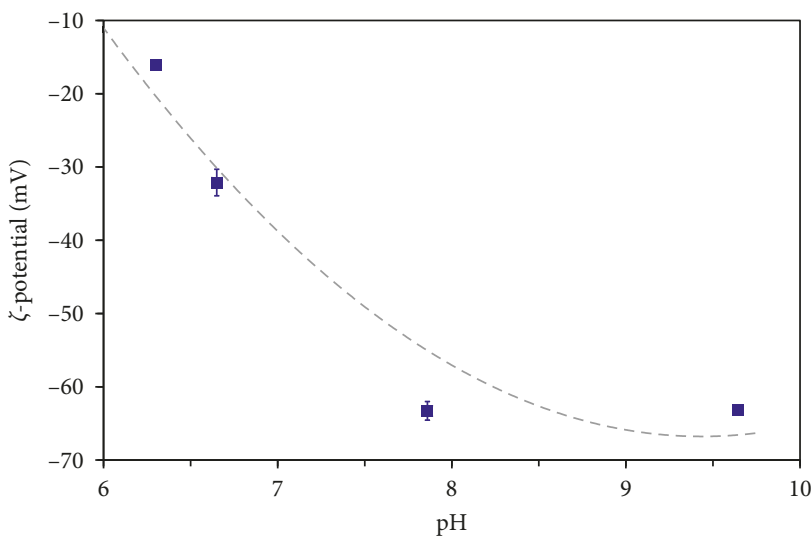

(b)

Figure 2: (a) Nitrogen adsorption/desorption isotherm and pore size distribution and (b) Zeta potential of Al-waste-NaP1.

2.2.4. Effect of Initial Adsorbate Concentration. The effect of the initial ammonium concentration was studied for the optimal adsorption conditions (i.e., pH 7.5; $15 \mathrm{~min} ; 10 \mathrm{~g} / \mathrm{L}$ ). The adsorption equilibrium experiments were determined by varying the initial adsorbate concentration between 10 and $1500 \mathrm{mg} / \mathrm{L}$ and evaluating different isotherm models.

After the adsorption process, the zeolite was separated from the adsorbate solutions by filtration. In order to ensure reliability and reproducibility of the experimental data, all the adsorption tests performed by duplicate and average values are reported in this work. The ammonium removal efficiency (expressed in \%) and the amount of ammonium adsorbed on $\mathrm{NaP} 1$ at any time $\left(q_{t}\right.$, expressed in $\left.\mathrm{mg} / \mathrm{g}\right)$ and at equilibrium $\left(q_{\mathrm{e}}\right.$, in $\mathrm{mg} / \mathrm{g}$ ) were calculated as follows:

$$
\begin{aligned}
\operatorname{Removal}(\%) & =\left(\frac{C_{\mathrm{o}}-C_{t}}{C_{\mathrm{o}}}\right) \cdot 100, \\
q_{t} & =\frac{\left(C_{\mathrm{o}}-C_{t}\right)}{m} \cdot V, \\
q_{\mathrm{e}} & =\frac{\left(C_{\mathrm{o}}-C_{\mathrm{e}}\right)}{m} \cdot V,
\end{aligned}
$$

where $C_{\mathrm{o}}(\mathrm{mg} / \mathrm{L})$ is the initial concentration of ammonium, $C_{t}$ and $C_{\mathrm{e}}(\mathrm{mg} / \mathrm{L})$ are the ammonium concentrations at 
contact time $t$ and at equilibrium, respectively, $m(\mathrm{~g})$ is the mass of zeolite, and $V(\mathrm{~L})$ is the volume of adsorbate solution.

2.3. Kinetic and Isotherm Modeling. The parameters and constants of the applied kinetic and isotherm models were determined by the nonlinear regression method, which is more accurate than the linear method, using the GRG nonlinear solving method of Microsoft Excel Solver. Applying nonlinear models can give more reliable results, minimizing the bias between the adsorption capacity values obtained from experimental data and those calculated from model equations.

2.3.1. Adsorption Kinetics. The study of the adsorption kinetic of ammonium on $\mathrm{NaP} 1$ was mathematically analyzed by applying the pseudo-first-order [21] and pseudo-secondorder [22] models, according to the following nonlinearized equations:

$$
\begin{aligned}
& q_{t}=q_{\mathrm{e}}\left(1-e^{k_{1} t}\right), \\
& q_{t}=\frac{k_{2} q_{\mathrm{e}}^{2} t}{1+k_{2} q_{\mathrm{e}} t},
\end{aligned}
$$

where $q_{\mathrm{e}}(\mathrm{mg} / \mathrm{g})$ and $q_{t}(\mathrm{mg} / \mathrm{g})$ are the amount of ammonium adsorbed per mass of zeolite at equilibrium and any time $t(\mathrm{~min})$, respectively, and $k_{1}(1 / \mathrm{min})$ and $k_{2}(\mathrm{~g} / \mathrm{mg} \mathrm{min})$ are the rate constants for the pseudo-first-order and pseudosecond order models.

2.3.2. Adsorption Isotherms. The relationship between the ammonium concentration in solution (liquid phase) and the zeolite (solid phase) at constant $\mathrm{pH}$ and temperature was studied by several adsorption isotherm models. To determine the best isotherm model fit, the experimental equilibrium data were analyzed by applying isotherm models with two-parameter equations (Freundlich, Langmuir, and Temkin) and with three-parameter equations (RedlichPeterson, Sips, and Toth) widely reported in the literature $[23,24]$.

Concerning the two-parameter models, the Freundlich isotherm is widely used and it describes heterogeneous adsorption systems [25]. The nonlinearized form of the Freundlich isotherm is expressed by the following equation:

$$
q_{\mathrm{e}}=k_{\mathrm{F}} C_{\mathrm{e}}^{n}
$$

where $q_{\mathrm{e}}(\mathrm{mg} / \mathrm{g})$ is the amount of ammonium adsorbed on the zeolite at equilibrium, $C_{e}(\mathrm{mg} / \mathrm{L})$ is the ammonium concentration at equilibrium, $k_{\mathrm{F}}(\mathrm{mg} / \mathrm{g}) /(\mathrm{mg} / \mathrm{L})^{n}$ is the Freundlich constant, and $n$ (dimensionless) is the Freundlich intensity parameter which indicates the magnitude of the adsorption driving force or the surface heterogeneity.

The Langmuir isotherm has been commonly used for the removal of a wide variety of compounds from waters using different adsorbents. It assumes monolayer coverage of adsorbate over a homogeneous adsorbent surface [26]. The nonlinearized model of Langmuir is described as follows:

$$
q_{\mathrm{e}}=\frac{q_{\mathrm{max}} k_{\mathrm{L}} C_{\mathrm{e}}}{1+k_{\mathrm{L}} C_{\mathrm{e}}},
$$

where $q_{\mathrm{e}}(\mathrm{mg} / \mathrm{g})$ is the amount of ammonium adsorbed on the zeolite at equilibrium, $q_{\max }(\mathrm{mg} / \mathrm{g})$ is the maximum monolayer adsorption capacity of the zeolite, $C_{\mathrm{o}}$ and $C_{\mathrm{e}}$ $(\mathrm{mg} / \mathrm{L})$ are the initial and equilibrium concentrations of ammonium, and $k_{\mathrm{L}}(\mathrm{L} / \mathrm{mg})$ is a constant related to the affinity between the adsorbent and adsorbate. The Langmuir isotherm model expressed extensively in terms of the separation factor or equilibrium parameter $\left(R_{\mathrm{L}}\right)$ [27] can be given by the following expression:

$$
R_{\mathrm{L}}=\frac{1}{1+k_{\mathrm{L}} C_{\mathrm{o}}} .
$$

The nature of the adsorption can be estimated through the isotherm profile according to the values of $R_{\mathrm{L}}$ and the Freundlich exponent $(n)$, being irreversible $\left(R_{\mathrm{L}}=0\right)$, favourable $\left(0<R_{\mathrm{L}}<1\right)$, linear $\left(R_{\mathrm{L}}=1\right)$, or unfavorable $\left(R_{\mathrm{L}}>1\right)$ [28]. The Langmuir theory can be applied to homogeneous adsorption where each adsorbed species involves the same sorption activation energy.

The Temkin model [29] is related to the effects of indirect interactions between adsorbent and adsorbate and is characterized by a uniform distribution of binding energies according to the following expression:

$$
q_{\mathrm{e}}=\frac{R T}{b} \ln \left(A C_{\mathrm{e}}\right)
$$

where $\mathrm{A}$ is the equilibrium binding constant $(\mathrm{L} / \mathrm{g}), b$ is related to the heat of adsorption $(\mathrm{J} / \mathrm{mol}), R$ is the gas constant $(8.314 \mathrm{~J} / \mathrm{K} \mathrm{mol})$, and $T$ is the temperature $(\mathrm{K})$.

Among the isotherm models with three parameters, the Redlich-Peterson isotherm [30] can be applied for both homogeneous and heterogeneous adsorption systems in a wide concentration range according to the following equation:

$$
q_{\mathrm{e}}=\frac{k_{\mathrm{RP}} C_{\mathrm{e}}}{1+a_{\mathrm{RP}} C_{\mathrm{e}}^{\beta}},
$$

where $k_{\mathrm{RP}}(\mathrm{L} / \mathrm{g})$ and $a_{\mathrm{RP}}(\mathrm{mg} / \mathrm{L})^{-\beta}$ are the Redlich-Peterson constants and $\beta$ (dimensionless) is an exponent whose value must lie between 0 and 1 . This model tends to the Langmuir isotherm when the exponent $\beta=1$, while it is described by the Freundlich isotherm when $k_{\mathrm{RP}}$ and $a_{\mathrm{RP}}$ are higher than 1 and $\beta$ is 1 [23].

The Sips isotherm [31] combines the Langmuir and Freundlich isotherms, leading to the Freundlich isotherm at low adsorbate concentrations, while it approaches Langmuir isotherm at high concentrations. The nonlinearized expression of the Sips isotherm can be represented by the following equation:

$$
q_{\mathrm{e}}=\frac{q_{\mathrm{max}}\left(k_{\mathrm{S}} C_{\mathrm{e}}\right)^{n}}{1+\left(k_{\mathrm{S}} C_{\mathrm{e}}\right)^{n}},
$$

where $q_{\max }(\mathrm{mg} / \mathrm{g})$ is the maximum adsorption capacity of the zeolite, $k_{\mathrm{S}}(\mathrm{L} / \mathrm{mg})$ is the Sips constants, $C_{\mathrm{e}}(\mathrm{mg} / \mathrm{L})$ is the ammonium concentration at equilibrium, and $n$ (dimensionless) is an exponent. 
The Toth isotherm [32] can be considered as the improved form of the Langmuir and Freundlich models, given by the following nonlinear expression:

$$
q_{\mathrm{e}}=\frac{q_{\mathrm{max}} k_{\mathrm{T}} C_{\mathrm{e}}}{\left[1+\left(k_{\mathrm{T}} C_{\mathrm{e}}\right)^{n}\right]^{1 / \mathrm{n}}},
$$

where $q_{\max }(\mathrm{mg} / \mathrm{g})$ is the maximum adsorption capacity of the zeolite, $C_{\mathrm{e}}(\mathrm{mg} / \mathrm{L})$ is the ammonium concentration at equilibrium, $k_{\mathrm{T}}(\mathrm{L} / \mathrm{mg})$ is the Toth isotherm constant, and $n$ (dimensionless) is the Toth exponent [33].

2.3.3. Error Functions. The goodness of fit of the kinetic and isotherm equations to the experimental data was evaluated using the coefficient of determination $\left(R^{2}\right)$, chi-square test $\left(\chi^{2}\right)$, root-mean-square error (RMSE), and hybrid error function (HYBRID), according to the following equations:

$$
\begin{aligned}
R^{2} & =1-\left[\frac{\sum_{i=1}^{n}\left(q_{i, \text { exp }}-q_{i, \text { model }}\right)^{2}}{\sum_{i=1}^{n}\left(q_{i, \exp }-\overline{q_{i, \exp }}\right)^{2}}\right], \\
\chi^{2} & =\sum_{i=1}^{n} \frac{\left(q_{i, \exp }-q_{i, \text { model }}\right)^{2}}{q_{i, \exp }}, \\
\text { RMSE } & =\sqrt{\left(\frac{1}{n-p}\right) \sum_{i=1}^{n}\left(q_{i, \exp }-q_{i, \text { model }}\right)^{2}}, \\
\text { HYBRID } & =\left(\frac{100}{n-p}\right) \sum_{i=1}^{n} \frac{\left(q_{i, \exp }-q_{i, \text { model }}\right)^{2}}{q_{i, \exp }},
\end{aligned}
$$

where $n$ is the number of experimental values in a dataset, $q_{i \text {,exp }}$ and $q_{i \text {,model }}$ are the experimental and calculated adsorption capacities, respectively, and $p$ is the number of parameters contained within the model.

All the parameters and constants of the applied models were determined by maximizing the error function in the case of using $R^{2}$ or minimizing the error values for $\chi^{2}$, RMSE, and HYBRID.

2.4. Analysis Techniques. Crystalline and morphological properties of Al-waste-NaP1 were analyzed by XRD (D8 Advance, Bruker) and SEM (S4800, Hitachi). Its textural characterization was evaluated by $\mathrm{N}_{2}$ adsorption/desorption analysis at $77 \mathrm{~K}$ (ASAP 2010, Micromeritics), previously outgassing at $350^{\circ} \mathrm{C}$ for $24 \mathrm{~h}$. The BET specific surface area $\left(S_{\mathrm{BET}}\right)$ and external area $\left(S_{\mathrm{EXT}}\right)$ of the zeolite were obtained by the BET method and t-plot analysis. The pore size distribution was calculated using the Barrett-Joyner-Halenda method. The $\zeta$-potential of the zeolite surface was measured (ZetaSizer Nano, Malvern) using the Smoluchowski approximation by preparing aqueous suspensions that contain $0.05 \mathrm{~g}$ of zeolite in $100 \mathrm{~mL}$ of aqueous solutions at different $\mathrm{pH}$ values. Before the $\zeta$-potential measurements, the zeolite suspensions were stirred in an ultrasonic bath $(60 \mathrm{~min})$ and then kept in contact for a long time $(>15 \mathrm{~h})$ to achieve the suspensions homogenization and stabilization. Suspensions with absolute $\zeta$-potential values of $30 \mathrm{mV}$ can be considered electrically stable, resulting in an adequately separation of low charged surfaces from highly charged surfaces [34]. The variation of the concentrations of $\mathrm{NH}_{4}{ }^{+}$before and after the adsorption experiments was determined colorimetrically with Nessler reagent by UV-Vis spectroscopy (Varian, Cari 1E) monitoring the absorbance at a wavelength of maximum absorbance $(420 \mathrm{~nm})$. The $\mathrm{pH}$ values of all experiments were adjusted by adding aqueous solutions of dilute $\mathrm{NaOH}$ or $\mathrm{HCl}$, using a $\mathrm{pH}$ meter (Crison, MM41). The immobilization of the adsorbate on the adsorbent was studied by Fourier transform infrared (FTIR) spectroscopy (Nicolet Nexus 670-870) on $\mathrm{KBr}$ discs.

\section{Results and Discussion}

3.1. Effect of $p H$. The $\mathrm{pH}$ plays a very important role in adsorption processes since it influences the chemical equilibrium between the ammonium ion $\left(\mathrm{NH}_{4}{ }^{+}\right)$and ammonia $\left(\mathrm{NH}_{3}\right)$, according to the reversible reaction [35]:

$$
\mathrm{NH}_{3}+\mathrm{H}_{2} \mathrm{O} \leftrightarrow \mathrm{NH}_{4}^{+}+\mathrm{OH}^{-} \text {. }
$$

Likewise, the $\mathrm{pH}$ also promotes electrostatic interactions between sorbent materials and ions to be adsorbed, being an essential control parameter in adsorption processes. The influence of $\mathrm{pH}$ on the ammonium adsorption capacity and removal efficiency for $\mathrm{NaP} 1$ was evaluated in the $\mathrm{pH}$ range of 6-8 (Figure 3 ) in order to select the most adequate conditions for further adsorption experiments. Although the highest ammonium uptake was reached at $\mathrm{pH} 7.5$ leading to the highest adsorption capacity $(8.76 \mathrm{mg} / \mathrm{g})$ and removal efficiency $(87.6 \%)$, similar results were also obtained at $\mathrm{pH} 7$ and 8. Thus, the $\mathrm{NH}_{4}{ }^{+}$adsorption capacity for $\mathrm{NaP1}$ was of 8.70 and $8.69 \mathrm{mg} / \mathrm{g}$ at $\mathrm{pH} 7$ and 8 , involving removal percentages of 87.0 and $86.9 \%$, respectively. Similarly, the $\mathrm{NH}_{4}{ }^{+}$ adsorption onto $\mathrm{NaA}$ zeolite from fly ash using the same adsorbate initial concentration $(50 \mathrm{mg} / \mathrm{L})$ also showed the best results at $\mathrm{pH}$ ranged between 7 and 8 (removal efficiency around 60\%) [36]. In our case, using Al-waste-NaP1 led to higher removal efficiency $(87.6 \%)$. Thus, the removal of the adsorbate from aqueous medium onto NaP1 could take place effectively at $\mathrm{pH} 7.5 \pm 0.5$. The adsorption ability of $\mathrm{NaP} 1$ decreased slightly (only 3\% less than the highest removal efficiency) as the $\mathrm{pH}$ decreased from 7.5 to 6 . This can be associated with the potential competition between $\mathrm{H}^{+}$ protons and the $\mathrm{NH}_{4}{ }^{+}$cations to be adsorbed onto $\mathrm{NaP} 1$. Similar tendencies were shown for the ammonium sorption onto other adsorbent materials, such as volcanic tuff whose main component is clinoptilolite [37] and NaA zeolite from halloysite mineral prepared by a two-step synthesis treatment (alkaline fusion followed by hydrothermal synthesis) [38]. Lower $\mathrm{pH}$ conditions were not considered in this work since previous studies have reported mass losses by dissolution as well as dealumination of zeolites at low $\mathrm{pH}$ values, especially at $\mathrm{pH}<4[14]$. Strong basic conditions $(\mathrm{pH}>8)$ were not evaluated since the $\mathrm{NH}_{4}{ }^{+}$concentration could decrease and the chemical equilibrium would be directed to the $\mathrm{NH}_{3}$ (g) formation. Therefore, the fixed $\mathrm{pH}$ for further 


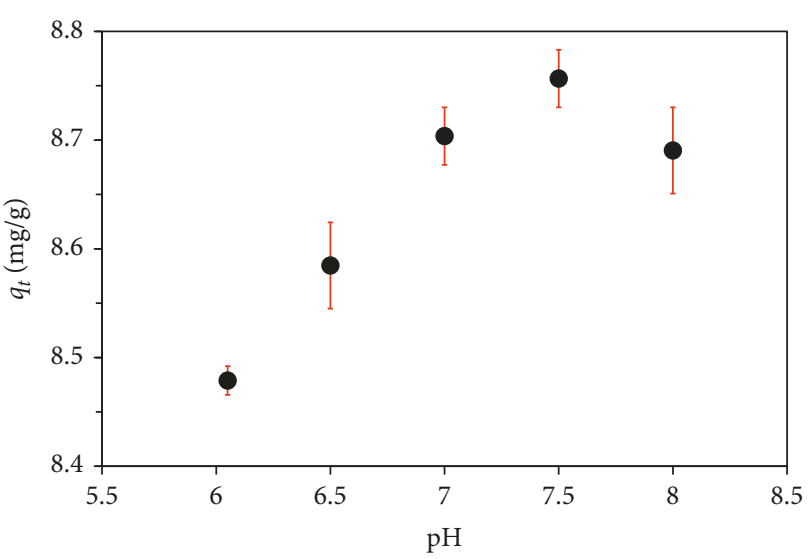

(a)



(b)

FIGURE 3: Influence of the solution $\mathrm{pH}$ on the $\mathrm{NH}_{4}{ }^{+}$adsorption capacity and removal efficiency of Al-waste-NaP1. Conditions: contact time $=15 \mathrm{~min}$; adsorbent dose $=5 \mathrm{~g} / \mathrm{L} ; \mathrm{Co}=50 \mathrm{mg} / \mathrm{L} ; \mathrm{T}=28 \pm 2^{\circ} \mathrm{C}$.

adsorption tests was 7.5 , where the zeolite mass remains unchanged and the adsorbate would exist mainly in the ionized form, that is, $\mathrm{NH}_{4}{ }^{+}$. The driving forces for the adsorption process would be described by electrostatic interactions and cation exchange mechanisms. In this sense, the electrostatic attraction would take place between the $\mathrm{NH}_{4}{ }^{+}$cations and the zeolitic adsorbent, whose surface is negatively charged in the studied $\mathrm{pH}$ range, as shown in the $\zeta$-potential analysis. On the other hand, the adsorbate $\left(\mathrm{NH}_{4}{ }^{+}\right)$and alkali metals (mainly $\mathrm{Na}^{+}$) from the zeolitic framework would be exchanged easily since these cations have similar crystal $\left(1.48\right.$ and $0.95 \AA$ for $\mathrm{NH}_{4}^{+}$and $\mathrm{Na}^{+}$, resp.) and hydrated radii (3.31 and $3.58 \AA$ for $\mathrm{NH}_{4}{ }^{+}$and $\mathrm{Na}^{+}$) [39], thus balancing the total charge of $\mathrm{NaP} 1$. The adsorption would involve trapping the $\mathrm{NH}_{4}^{+}$cations inside the NaP1 structure, releasing innocuous cations (like $\mathrm{Na}^{+}$) to the aqueous medium:

$$
\text { Zeolite }-\mathrm{Na}^{+}+\mathrm{NH}_{4}{ }^{+} \leftrightarrow \mathrm{Na}^{+}+\text {Zeolite }-\mathrm{NH}_{4}{ }^{+} .
$$

Structurally, the zeolite presents 8-ring pore apertures that would be large enough for the accessibility of certain cations like $\mathrm{NH}_{4}{ }^{+}$through the zeolite channel system. The $\mathrm{NH}_{4}{ }^{+}$ immobilization on $\mathrm{NaP} 1$ was studied by the FTIR analysis, comparing the FTIR spectrum of initial Al-waste-NaP1 with that obtained after the uptake of the adsorbate, as shown in Figure 4. Before $\mathrm{NH}_{4}{ }^{+}$adsorption, the zeolite shows the assignments of the main absorption bands of NaP1: T-O-T asymmetrical stretching mode $\left(\sim 1000 \mathrm{~cm}^{-1}\right)$, T-O-T symmetrical stretching mode $\left(740-680 \mathrm{~cm}^{-1}\right)$, external linkage vibration $\left(\sim 607 \mathrm{~cm}^{-1}\right)$, and $\mathrm{T}-\mathrm{O}$ bending mode $\left(430 \mathrm{~cm}^{-1}\right)$ of the $\mathrm{TO}_{4}$ tetrahedron [10]. The $\mathrm{NH}_{4}{ }^{+}$adsorption process led to very similar absorption bands (represented by dashed lines in Figure 4) to the characteristic vibration modes occurring in the NaP1 framework before adsorption. The results confirmed that the main change was observed at approximately $1400 \mathrm{~cm}^{-1}$, attributing to the absorption band ( $v 4$ asymmetrical bending mode) of $\mathrm{NH}_{4}{ }^{+}$present in the $\mathrm{NaP} 1$ structure [40]. Therefore, the cation exchange of $\mathrm{Na}^{+}$by $\mathrm{NH}_{4}{ }^{+}$may be considered as the governing mechanism of the adsorption process, as shown in Figure 5.



FIgURE 4: FTIR spectra of Al-waste-NaP1 (a) before and (b) after $\mathrm{NH}_{4}{ }^{+}$adsorption.

3.2. Effect of Contact Time: Adsorption Kinetics. The influence of the contact time on the ammonium removal efficiency was studied from 1 to $360 \mathrm{~min}$, as shown in Figure 6(a). The ammonium adsorption on Al-waste-NaP1 seems to be a very fast process where the equilibrium was reached within the first $5 \mathrm{~min}$. Under the tested operating conditions, the highest removal efficiency of the zeolite was $88 \%$, which was reached at $15 \mathrm{~min}$. The short required contact time would involve a high affinity for the adsorbate, indicating a close electrostatic interaction between the $\mathrm{NH}_{4}{ }^{+}$ cations and the charged negatively functional groups on the zeolite surface. As the contact time increased, the removal efficiency of Al-waste-NaP1 was almost constant (86.3 and $85.4 \%$ for 2 and $30 \mathrm{~min}$ ) and then slightly decreased from 82 to $75.8 \%$ for 60 and $360 \mathrm{~min}$. Some authors found that the $\mathrm{NH}_{4}{ }^{+}$adsorption efficiency using natural zeolite was maintained from $30 \mathrm{~min}$ to longer contact times (up to $24 \mathrm{~h}$ ) [41]. It seems to be related to the large number of available active sites on the adsorbent surface and the high adsorbate 


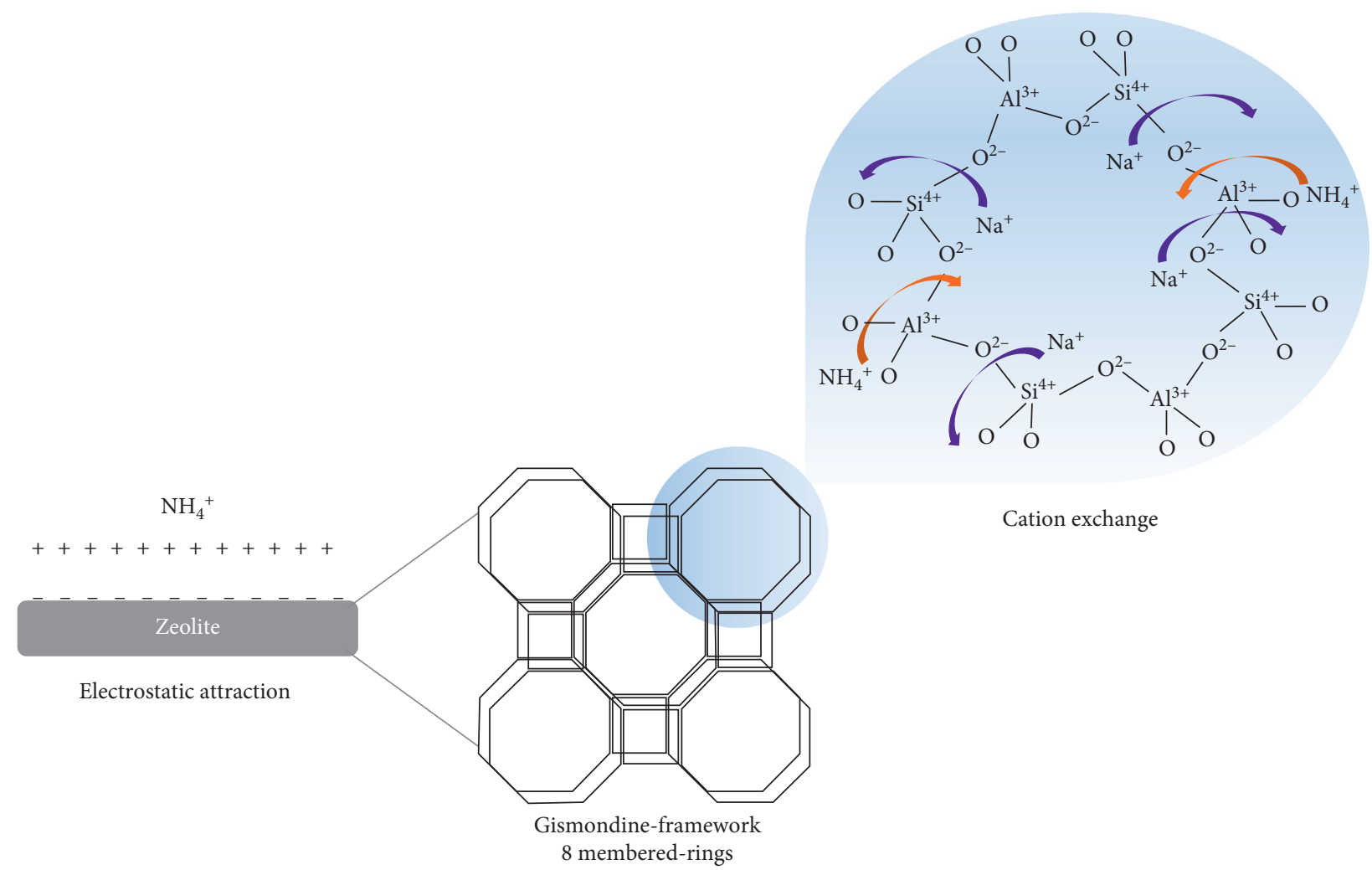

Figure 5: Adsorption mechanism through the cation exchange between the extra-framework cations $\left(\mathrm{Na}^{+}\right)$of the Al-waste-NaP1 zeolite and the ammonium cations $\left(\mathrm{NH}_{4}^{+}\right)$.

concentration gradient at the beginning of the adsorption process, resulting in a fast diffusion and rapid equilibrium. As the adsorbent sites are occupied, the adsorption capacity would decrease significantly. Additionally, the rapid adsorption would take place easily on the adsorbent surface, whereas the slower uptake process would occur inside the pores [42]. In this sense, as a further increase in the contact time had no significant effect on the removal efficiency, the adsorption kinetic of $\mathrm{NH}_{4}{ }^{+}$onto Al-waste-NaP1 was only studied between 1 and $60 \mathrm{~min}$. As the kinetic analysis is essential for the process design in water treatment applications, the adsorption kinetic performance was evaluated by applying the pseudo-first-order and pseudo-secondorder models, shown in Figure 6(b), using the nonlinear regression method. Apparently, minor differences can be noticed between the plots obtained for the pseudo-secondorder and the pseudo-first-order model. Generally, although in most of the reviewed works [42-45], the $\mathrm{NH}_{4}{ }^{+}$adsorption kinetic has been evaluated according to linear regression methods, the pseudo-second-order model seems to provide the best results. However, the pseudo-first-order equation is usually more appropriate for the initial stage of adsorption processes (contact time of $20-30 \mathrm{~min}$ ) not for the whole range [46]. In our case, the adsorption of $\mathrm{NH}_{4}{ }^{+}$on $\mathrm{Al}$-waste$\mathrm{NaP} 1$ was significantly rapid, reaching high efficiencies of 80.3 and $86.3 \%$ in 1 and $2 \mathrm{~min}$, respectively. Thus, the pseudo-first-order kinetic model seems to describe better the experimental data since this model provided a more accurate correlation, that is, the highest $R^{2}$ as well as the lowest $\chi^{2}$,
HYBRID, and RMSE values (Table 1). It is believed that the $\mathrm{NH}_{4}{ }^{+}$uptake by $\mathrm{NaP1}$ follows the common transport processes during the adsorption in solid-liquid systems characterized by four steps: (i) the bulk transport, which occurs quickly; (ii) the film diffusion where the adsorbate is transported from the bulk liquid phase to the active sites on the adsorbent external surface (solid phase), taking place slowly; (iii) the intraparticle diffusion where the adsorbate diffuses slowly from the exterior of the adsorbent to the most internal surface (i.e., pores) of the adsorbent; and (iv) the very fast adsorptive attachment [47].

3.3. Effect of Adsorbent Dose. The influence of the adsorbent dose on the removal efficiency and adsorption capacity of $\mathrm{NaP} 1$ for the ammonium uptake was studied from 1 to $15 \mathrm{~g} / \mathrm{L}$, as shown in Figure 7. The increase of the zeolite dose led to the increase of the removal efficiency from 61 to $92 \%$ for 1 and $15 \mathrm{~g} / \mathrm{L}$, while the $\mathrm{NH}_{4}{ }^{+}$uptake capacity decreased from 30.4 to $3.1 \mathrm{mg} / \mathrm{g}$ for 1 and $15 \mathrm{~g} / \mathrm{L}$, respectively. The higher the adsorbent mass, the larger the adsorbent surface, and accordingly, the larger the number of adsorption sites on the $\mathrm{NaP} 1$ surface is, accelerating the adsorption process. The $\mathrm{NH}_{4}{ }^{+}$cations would diffuse from the aqueous medium towards the surface of the adsorbent due to the electrostatic attraction, tending to occupy the adsorption active sites. In this context, the higher the adsorbent dose, the larger the adsorbent sites will be available under the same adsorption conditions (i.e., under the same adsorbate mass gradient). 


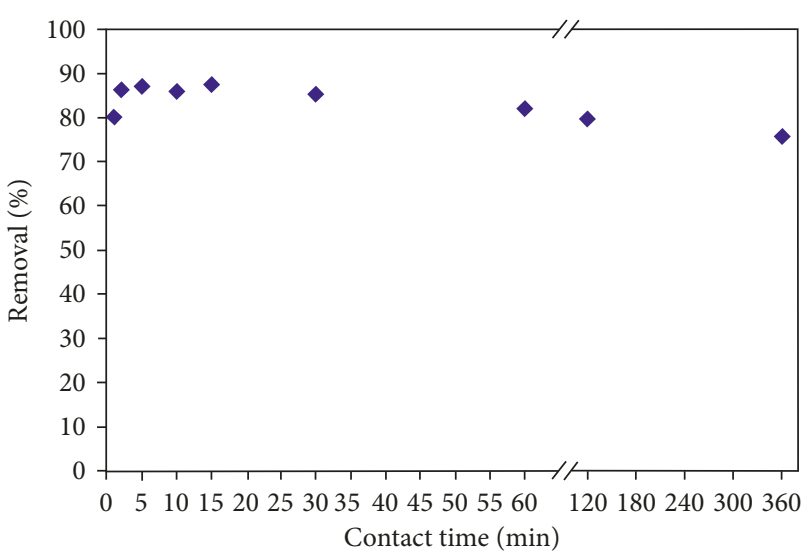

(a)



(b)

FIgURE 6: (a) Influence of the contact time and (b) kinetic modeling of the $\mathrm{NH}_{4}{ }^{+}$adsorption by $\mathrm{Al}$-waste- $\mathrm{NaP} 1$. Conditions: $\mathrm{pH}=7.5$; adsorbent dose $=5 \mathrm{~g} / \mathrm{L} ; \mathrm{Co}=50 \mathrm{mg} / \mathrm{L} ; \mathrm{T}=28 \pm 2^{\circ} \mathrm{C}$.

TABle 1: Kinetic model parameters and error function values obtained for the $\mathrm{NH}_{4}{ }^{+}$adsorption onto Al-waste-NaP1.

\begin{tabular}{lcccc}
\hline $\begin{array}{l}q_{\mathrm{e}, \text { experimental }} \\
(\mathrm{mg} / \mathrm{g})\end{array}$ & $\begin{array}{c}\text { Pseudo-first-order } \\
\text { model }\end{array}$ & \multicolumn{2}{c}{$\begin{array}{c}\text { Pseudo-second-order } \\
\text { model }\end{array}$} \\
\hline \multirow{4}{*}{8.75} & $\begin{array}{c}q_{\mathrm{e}, \mathrm{model}} \\
(\mathrm{mg} / \mathrm{g})\end{array}$ & 8.68 & $\begin{array}{c}q_{\mathrm{e}, \mathrm{model}} \\
(\mathrm{mg} / \mathrm{g})\end{array}$ & 8.87 \\
& $k_{1}(1 / \mathrm{min})$ & 2.60 & $k_{2}(\mathrm{~g} / \mathrm{mg} \mathrm{min})$ & 1.20 \\
& $R^{2}$ & 0.961 & $R^{2}$ & 0.895 \\
& $\chi^{2}$ & 0.022 & $\chi^{2}$ & 0.035 \\
& RMSE & 0.196 & RMSE & 0.246 \\
& HYBRID & 0.460 & HYBRID & 0.720 \\
\hline
\end{tabular}

These results are in agreement with values found by other researchers for the adsorption of ammonium onto a geopolymer-type adsorbent [42]. Both the removal efficiency and adsorption capacity of the zeolite were almost constant from 10 to $15 \mathrm{~g} / \mathrm{L}$; thus, the selected adsorbent dose for developing the further adsorption tests was $10 \mathrm{~g} / \mathrm{L}$ since it would be the lowest adsorbent dose that provides a very high removal efficiency (91\%).

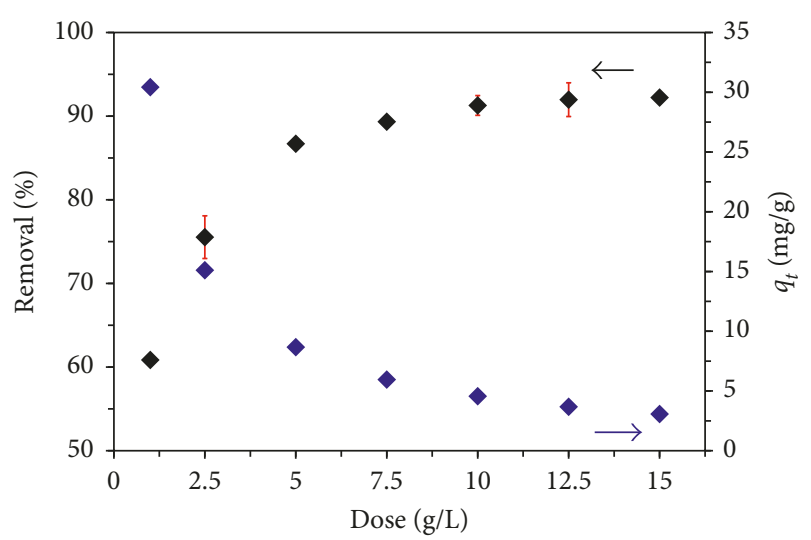

FIGURE 7: Influence of the adsorbent dose on the $\mathrm{NH}_{4}^{+}$removal efficiency and uptake capacity of $\mathrm{Al}$-waste-NaP1. Conditions: $\mathrm{pH}=7.5$; contact time $=15 \mathrm{~min} ; \mathrm{Co}=50 \mathrm{mg} / \mathrm{L} ; \mathrm{T}=28 \pm 2^{\circ} \mathrm{C}$.

3.4. Effect of Initial Adsorbate Concentration: Equilibrium Isotherms. As the initial concentration increased, the amount of ammonium retained by $\mathrm{Al}$-waste- $\mathrm{NaP} 1$ also increased gradually up to the adsorbent saturation, which was reached above an initial concentration of approximately $1000 \mathrm{mg} / \mathrm{L}$ under the tested conditions. The experimental data indicated that the maximum adsorption capacity of Alwaste- $\mathrm{NaP} 1$ was $37.9 \mathrm{mg} / \mathrm{g}$. In general, higher adsorption capacities are obtained from the fit of isotherm models to the experimental data. The applied adsorption isotherms are illustrated in Figure 8. The estimated parameters and error function values for the two-parameter and three-parameter models are shown in Table 2. The Langmuir isotherm was the only two-parameter model that provided the best data tendency in the whole range of initial concentrations. Thus, the Langmuir isotherm would indicate a homogeneous process and monolayer coverage of $\mathrm{NH}_{4}{ }^{+}$on the $\mathrm{NaP} 1$ surface. On the contrary, the Freundlich isotherm was only suited for the range of low initial concentrations, while the Temkin model was not fit satisfactorily to the experimental data. The relation between the Freundlich exponent $(n=0.48<1)$ and the Langmuir separation factor $\left(R_{\mathrm{L}}=0.94\right.$ and 0.11 for the lowest and highest initial adsorbate concentration) would indicate that the $\mathrm{NH}_{4}{ }^{+}$adsorption by Al-waste-NaP1 was favorable, according to the concave isotherm shape followed by experimental data $[23,24]$. The experimental data were described adequately by all the three-parameter models. Such models followed the same isotherm profile, providing the best fits for the experimental data. In particular, the Sips and Toth models provided the highest $R^{2}$ and the lowest $\chi^{2}$, HYBRID, and RMSE values. The results show that the maximum amount of adsorbed $\mathrm{NH}_{4}{ }^{+}$cation per mass of $\mathrm{NaP} 1$ (i.e., $q_{\text {max }}$ ) was of 54.19 and $58.46 \mathrm{mg} / \mathrm{g}$, according to the Sips and Toth isotherms, respectively. The Sips isotherm provided reliable results possibly due to the fact it combines both the Langmuir and Freundlich models, thus covering satisfactorily the whole initial concentration range. Thus, the $\mathrm{NH}_{4}{ }^{+}$adsorption using Al-waste-NaP1 could be described by a homogeneous and heterogeneous process. The Redlich-Peterson isotherm is also a combination of both Langmuir and Freundlich 


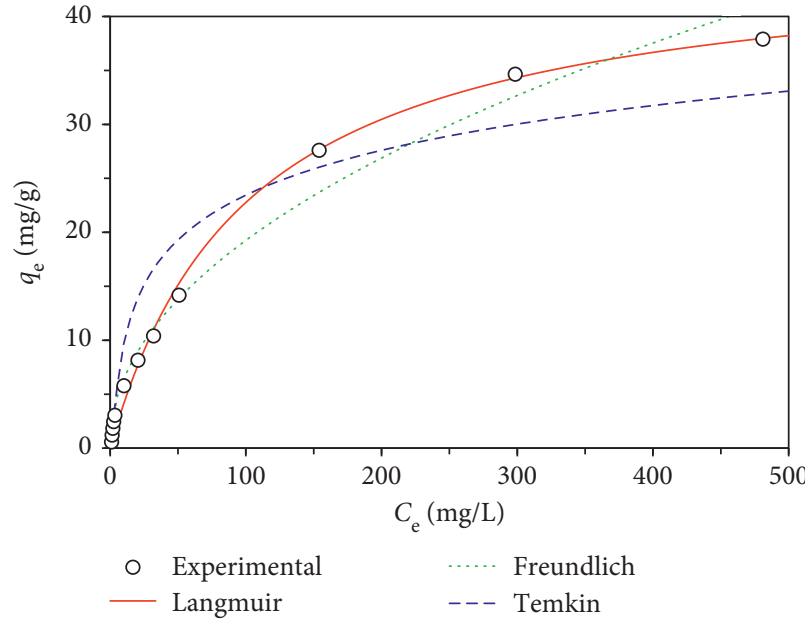

(a)

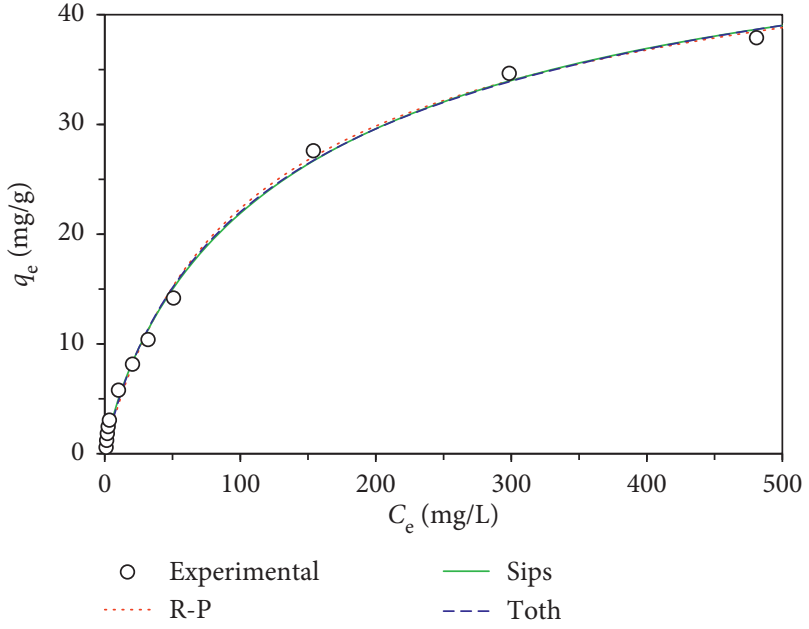

(b)

Figure 8: Adsorption isotherms for the $\mathrm{NH}_{4}{ }^{+}$uptake on Al-waste-NaP1. Conditions: $\mathrm{pH}=7.5$; contact time $=15$ min; adsorbent dos$\mathrm{e}=10 \mathrm{~g} / \mathrm{L}$; and $\mathrm{T}=28 \pm 2^{\circ} \mathrm{C}$. R-P: Redlich-Peterson.

TABLE 2: Isotherm models applied for the $\mathrm{NH}_{4}{ }^{+}$adsorption onto Al-waste-NaP1.

\begin{tabular}{|c|c|c|c|c|c|c|c|}
\hline \multicolumn{4}{|c|}{ Two-parameter isotherm model } & \multicolumn{4}{|c|}{ Error function } \\
\hline \multirow{2}{*}{ Langmuir } & $q_{\max }(\mathrm{mg} / \mathrm{g})$ & $k_{\mathrm{L}}(\mathrm{L} / \mathrm{mg})$ & & $R^{2}$ & $\chi^{2}$ & RMSE & HYBRID \\
\hline & 46.05 & 0.01 & & 0.995 & 3.291 & 0.993 & 25.228 \\
\hline \multirow{2}{*}{ Freundlich } & $k_{\mathrm{F}}(\mathrm{mg} / \mathrm{g}) /(\mathrm{mg} / \mathrm{L})^{n}$ & $n$ & & $R^{2}$ & $x^{2}$ & RMSE & HYBRID \\
\hline & 2.09 & 0.48 & & 0.981 & 2.597 & 1.935 & 35.623 \\
\hline \multirow{2}{*}{ Temkin } & $A(\mathrm{~L} / \mathrm{g})$ & $b(\mathrm{~J} / \mathrm{mol})$ & & $R^{2}$ & $\chi^{2}$ & RMSE & HYBRID \\
\hline & 0.50 & 413.74 & & 0.901 & 11.384 & 4.453 & 179.190 \\
\hline \multicolumn{4}{|c|}{ Three-parameter isotherm model } & \multicolumn{4}{|c|}{ Error function } \\
\hline \multirow{2}{*}{ Sips } & $q_{\max }(\mathrm{mg} / \mathrm{g})$ & $k_{\mathrm{S}} \times 10^{-3}(\mathrm{~L} / \mathrm{mg})$ & $n$ & $R^{2}$ & $\chi^{2}$ & RMSE & HYBRID \\
\hline & 54.19 & 6.26 & 0.83 & 0.997 & 0.739 & 0.804 & 9.533 \\
\hline \multirow{2}{*}{ Toth } & $q_{\max }(\mathrm{mg} / \mathrm{g})$ & $k_{\mathrm{T}} \times 10^{-2}(\mathrm{~L} / \mathrm{mg})$ & $n$ & $R^{2}$ & $x^{2}$ & RMSE & HYBRID \\
\hline & 58.46 & 1.10 & 0.68 & 0.996 & 0.833 & 0.935 & 10.026 \\
\hline \multirow{2}{*}{ Redlich-Peterson } & $k_{\mathrm{RP}}(\mathrm{L} / \mathrm{g})$ & $a_{\mathrm{RP}}(\mathrm{mg} / \mathrm{L})^{-\beta}$ & $\beta$ & $R^{2}$ & $\chi^{2}$ & RMSE & HYBRID \\
\hline & 0.52 & 0.02 & 0.91 & 0.996 & 0.979 & 1.002 & 11.399 \\
\hline
\end{tabular}

TABle 3: Ammonium adsorption capacity for several adsorbents.

\begin{tabular}{lccccccc}
\hline Adsorbent & $q_{\max }(\mathrm{mg} / \mathrm{g})$ & Isotherm & $\mathrm{pH}$ & $T\left({ }^{\circ} \mathrm{C}\right)$ & Time $(\mathrm{min})$ & Dose $(\mathrm{g} / \mathrm{L})$ & Reference \\
\hline Natural zeolite & 10.39 & Langmuir & 7 & 25 & 1440 & 32 & Mazloomi and Jalali [48] \\
Geopolymer & 21.07 & Sips & 6 & 22 & 1440 & 5 & Luukkonen et al. [42] \\
Modified biochar & 22.6 & Langmuir & $8-9$ & - & 120 & 2 & Vu et al. [6] \\
Natural zeolite & 23.83 & Sips & 6.5 & 25 & 1440 & 3 & Lei et al. [45] \\
Fly-ash zeolite & 37.45 & Langmuir & 8 & 25 & 75 & 4 & Zhang et al. [49] \\
Hydrogel & 42.74 & Langmuir & $6-7$ & 30 & 30 & 15 & Zheng et al. [43] \\
Al-waste-NaP1 & 54.19 & Sips & 7.5 & 28 & 60 & This work \\
Fly ash-zeolite & 95.42 & Langmuir & 7 & 25 & Jiang et al. [36] \\
\hline
\end{tabular}

models [24]. As the Redlich-Peterson exponent was close to 1 $(\beta=0.91)$, the process would be best described by the Langmuir isotherm instead of Freundlich [23]. Therefore, it is believed that the adsorption of the $\mathrm{NH}_{4}{ }^{+}$cation onto this zeolite can be more homogeneous rather than heterogeneous.

3.5. Comparison of the $\mathrm{NH}_{4}{ }^{+}$Removal Capacity of Al-WasteNaP1 with Other Adsorbents. The maximum $\mathrm{NH}_{4}{ }^{+}$removal capacity of the studied zeolite was compared with other adsorbent materials (Table 3). Although different operating conditions have been used for the uptake of $\mathrm{NH}_{4}{ }^{+}$, in general, the results show that the required time to remove the adsorbate by Al-waste-NaP1 was shorter than most of the adsorbents given in Table 3. As can be seen, lower and higher $\mathrm{NH}_{4}{ }^{+}$adsorption capacities were found in the literature. The NaP1 adsorbent from Al-waste under effluents recycling showed a high removal capacity, being generally 
higher than natural zeolites. In addition, it can be considered as a low-cost adsorbent compared to other commercial materials like activated carbons. The studied NaP1 zeolite exhibited adequate sorption properties when it is compared to other sorbent materials obtained from common synthesis processes without recycling of effluents. In this sense, Alwaste-NaP1 showed promising adsorption characteristics, making it a potential adsorbent for the $\mathrm{NH}_{4}{ }^{+}$removal from water. It is believed that this zeolite could be also used to remove other contaminants (e.g., heavy metals, radioactive metals, and organic compounds) in aqueous media.

\section{Conclusions}

In this work, the elimination of $\mathrm{NH}_{4}{ }^{+}$cation from aqueous solutions using the zeolite $\mathrm{NaP} 1$, which was synthesized from a hazardous Al-waste by an eco-friendly process, was studied by means of batch adsorption experiments. The effects of different experimental parameters, including $\mathrm{pH}$, contact time, adsorbent dose, and initial $\mathrm{NH}_{4}{ }^{+}$concentration, on the adsorption efficiency and adsorption capacity of Al-waste-NaP1 was studied under ambient conditions. The adsorption kinetic and equilibrium isotherms were also studied by applying the nonlinear method. The results showed that the uptake process of the adsorbate $\left(\mathrm{NH}_{4}{ }^{+}\right)$by the adsorbent (Al-waste- $\mathrm{NaP} 1)$ was fast leading to removal percentages of $88 \%$ in the first $15 \mathrm{~min}$. The $\mathrm{NH}_{4}{ }^{+}$removal on the zeolite was better described by the pseudo-first-order kinetic model. The experimental data showed that the highest amount of $\mathrm{NH}_{4}^{+}$cations removed by the zeolitic adsorbent was $37.9 \mathrm{mg} / \mathrm{g}$, similar to that found for other sorbent materials. The equilibrium data were better described by the three-parameter isotherm models than the two-parameter equations. In particular, the Sips and Toth isotherms led to maximum capacities of 54.19 and $58.46 \mathrm{mg} / \mathrm{g}$, respectively. Thus, a synergic effect on the environmental protection can be achieved: firstly, the transformation of the hazardous Al-waste into a zeolite can contribute to the end of waste condition, and secondly, the Al-waste-based zeolite can be considered as an alternative adsorbent to other materials used for the treatment of contaminated aqueous effluents.

\section{Data Availability}

The data used to support the findings of this study are available from the corresponding author upon request.

\section{Conflicts of Interest}

The authors declare that they have no conflicts of interest.

\section{Acknowledgments}

The authors thank MINECO for its financial support (Project CTM2012-34449). R. Sánchez-Hernández thanks MINECO for the grant BES-2013-066269. The authors thank the Research Support Centre of the Geology Faculty, University Complutense of Madrid, for the help given.

\section{References}

[1] J. K. Böhlke, R. L. Smith, and D. N. Miller, "Ammonium transport and reaction in contaminated groundwater: application of isotope tracers and isotope fractionation studies," Water Resources Research, vol. 42, no. 5, 2006.

[2] A. Casadellà, P. Kuntke, O. Schaetzle, and K. Loos, "Clinoptilolite-based mixed matrix membranes for the selective recovery of potassium and ammonium," Water Research, vol. 90, pp. 62-70, 2016.

[3] A. Urtiaga, I. Ortiz, A. Anglada, D. Mantzavinos, and E. Diamadopoulos, "Kinetic modeling of the electrochemical removal of ammonium and COD from landfill leachates," Journal of Applied Electrochemistry, vol. 42, no. 9, pp. 779786, 2012.

[4] M. Sica, A. Duta, C. Teodosiu, and C. Draghici, "Thermodynamic and kinetic study on ammonium removal from a synthetic water solution using ion exchange resin," Clean Technologies and Environmental Policy, vol. 16, no. 2, pp. 351-359, 2014.

[5] L. Megido, B. Suárez-Peña, L. Negral et al., "Relationship between physico-chemical characteristics and potential toxicity of PM10," Chemosphere, vol. 162, pp. 73-79, 2016.

[6] T. M. Vu, V. T. Trinh, D. P. Doan et al., "Removing ammonium from water using modified corncob-biochar," Science of the Total Environment, vol. 579, pp. 612-619, 2017.

[7] M. Ahmad, A. U. Rajapaksha, J. E. Lim et al., "Biochar as a sorbent for contaminant management in soil and water: a review," Chemosphere, vol. 99, pp. 19-33, 2014.

[8] S. Sen Gupta and K. G. Bhattacharyya, "Adsorption of metal ions by clays and inorganic solids," RSC Advances, vol. 4, no. 54, pp. 28537-28586, 2014.

[9] L. Lin, Z. Lei, L. Wang et al., "Adsorption mechanisms of high-levels of ammonium onto natural and $\mathrm{NaCl}$-modified zeolites," Separation and Purification Technology, vol. 103, pp. 15-20, 2013.

[10] R. Sánchez-Hernández, A. López-Delgado, I. Padilla, R. Galindo, and S. López-Andrés, "One-step synthesis of $\mathrm{NaP1}$, SOD and ANA from a hazardous aluminum solid waste," Microporous and Mesoporous Materials, vol. 226, pp. 267-277, 2016.

[11] J. Tian, V. Miller, P. C. Chiu, J. A. Maresca, M. Guo, and P. T. Imhoff, "Nutrient release and ammonium sorption by poultry litter and wood biochars in stormwater treatment," Science of the Total Environment, vol. 553, pp. 596-606, 2016.

[12] S. Wang and Y. Peng, "Natural zeolites as effective adsorbents in water and wastewater treatment," Chemical Engineering Journal, vol. 156, no. 1, pp. 11-24, 2010.

[13] T. H. Martins, T. S. O. Souza, and E. Foresti, “Ammonium removal from landfill leachate by Clinoptilolite adsorption followed by bioregeneration," Journal of Environmental Chemical Engineering, vol. 5, no. 1, pp. 63-68, 2017.

[14] R. Leyva-Ramos, J. E. Monsivais-Rocha, A. Aragon-Piña et al., "Removal of ammonium from aqueous solution by ion exchange on natural and modified chabazite," Journal of Environmental Management, vol. 91, no. 12, pp. 2662-2668, 2010.

[15] R. Malekian, J. Abedi-Koupai, S. S. Eslamian, S. F. Mousavi, K. C. Abbaspour, and M. Afyuni, "Ion-exchange process for ammonium removal and release using natural Iranian zeolite," Applied Clay Science, vol. 51, no. 3, pp. 323-329, 2011.

[16] N. Koshy and D. N. Singh, "Fly ash zeolites for water treatment applications," Journal of Environmental Chemical Engineering, vol. 4, no. 2, pp. 1460-1472, 2016. 
[17] R. Sánchez-Hernández, I. Padilla, S. López-Andrés, and A. López-Delgado, "Eco-friendly bench-scale zeolitization of an Al-containing waste into gismondine-type zeolite under effluent recycling," Journal of Cleaner Production, vol. 161, pp. 792-802, 2017.

[18] X. You, C. Valderrama, and J. L. Cortina, "Simultaneous recovery of ammonium and phosphate from simulated treated wastewater effluents by activated calcium and magnesium zeolites," Journal of Chemical Technology and Biotechnology, vol. 92, no. 9, pp. 2400-2409, 2017.

[19] D. Guaya, C. Valderrama, A. Farran, C. Armijos, and J. L. Cortina, "Simultaneous phosphate and ammonium removal from aqueous solution by a hydrated aluminum oxide modified natural zeolite," Chemical Engineering Journal, vol. 271, pp. 204-213, 2015.

[20] M. Uğurlu and M. H. Karaoğlu, "Adsorption of ammonium from an aqueous solution by fly ash and sepiolite: isotherm, kinetic and thermodynamic analysis," Microporous and Mesoporous Materials, vol. 139, no. 1-3, pp. 173-178, 2011.

[21] S. Y. Lagergren, "Zur Theorie der sogenannten adsorption gelöster stoffe," Handlingar, vol. 24, no. 4, pp. 1-39, 1898.

[22] G. Blanchard, M. Maunaye, and G. Martin, "Removal of heavy metals from waters by means of natural zeolites," Water Research, vol. 18, no. 12, pp. 1501-1507, 1984.

[23] H. N. Tran, S.-J. You, A. Hosseini-Bandegharaei, and H.-P. Chao, "Mistakes and inconsistencies regarding adsorption of contaminants from aqueous solutions: a critical review," Water Research, vol. 120, pp. 88-116, 2017.

[24] K. Y. Foo and B. H. Hameed, "Insights into the modeling of adsorption isotherm systems," Chemical Engineering Journal, vol. 156, no. 1, pp. 2-10, 2010.

[25] H. M. F. Freundlich, "Over the adsorption in solution," Journal of Physical Chemistry, vol. 57, pp. 385-471, 1906.

[26] I. Langmuir, "The adsorption of gases on plane surfaces of glass, mica and platinum," Journal of the American Chemical Society, vol. 40, no. 9, pp. 1361-1403, 1918.

[27] K. R. Hall, L. C. Eagleton, A. Acrivos, and T. Vermeulen, "Poreand solid-diffusion kinetics in fixed-bed adsorption under constant-pattern conditions," Industrial and Engineering Chemistry Fundamentals, vol. 5, no. 2, pp. 212-223, 1966.

[28] E. Worch, Adsorption Technology in Water Treatment: Fundamentals, Processes, and Modeling, De Gruyter, Berlin, Germany, 2012.

[29] M. Temkin and V. Pyzhev, "Kinetics of ammonia synthesis on promoted iron catalysts," Acta Physiochim, vol. 12, pp. 217222, 1940.

[30] O. Redlich and D. L. Peterson, "A useful adsorption isotherm," Journal of Physical Chemistry, vol. 63, no. 6, p. 1024, 1959.

[31] R. Sips, "On the structure of a catalyst surface," Journal of Chemical Physics, vol. 16, no. 5, pp. 490-495, 1948.

[32] J. Toth, "State equations of the solid-gas interface layers," Acta Chimica Academiae Scientiarum Hungaricae, vol. 69, pp. 311-328, 1971.

[33] É. C. Lima, M. A. Adebayo, and F. M. Machado, "Kinetic and equilibrium models of adsorption," in Carbon Nanomaterials as Adsorbents for Environmental and Biological Applications, Springer, Berlin, Germany, 2015.

[34] O. Larlus, S. Mintova, and T. Bein, "Environmental syntheses of nanosized zeolites with high yield and monomodal particle size distribution," Microporous and Mesoporous Materials, vol. 96, no. 1-3, pp. 405-412, 2006.

[35] L. Y. Zhang, H. Y. Zhang, W. Guo, and Y. L. Tian, "Sorption characteristics and mechanisms of ammonium by coal by-products: slag, honeycomb-cinder and coal gangue," International Journal of Environmental Science and Technology, vol. 10, no. 6, pp. 1309-1318, 2013.

[36] Z. Jiang, J. Yang, H. Ma, X. Ma, and J. Yuan, "Synthesis of pure $\mathrm{NaA}$ zeolites from coal fly ashes for ammonium removal from aqueous solutions," Clean Technologies and Environmental Policy, vol. 18, no. 3, pp. 629-637, 2016.

[37] E. Marañón, M. Ulmanu, Y. Fernández, I. Anger, and L. Castrillón, "Removal of ammonium from aqueous solutions with volcanic tuff," Journal of Hazardous Materials, vol. 137, no. 3, pp. 1402-1409, 2006.

[38] Y. Zhao, B. Zhang, X. Zhang, J. Wang, J. Liu, and R. Chen, "Preparation of highly ordered cubic NaA zeolite from halloysite mineral for adsorption of ammonium ions," Journal of Hazardous Materials, vol. 178, no. 1-3, pp. 658-664, 2010.

[39] E. R. Nightingale, "Phenomenological theory of ion solvation. effective radii of hydrated ions," Journal of Physical Chemistry, vol. 63, no. 9, pp. 1381-1387, 1959.

[40] K. Nakamoto, "Applications in inorganic chemistry," in Infrared and Raman Spectra of Inorganic and Coordination Compounds, John Wiley \& Sons, Inc., Hoboken, NJ, USA, 2008.

[41] K. Saltalı, A. Sarı, and M. Aydın, "Removal of ammonium ion from aqueous solution by natural Turkish (Yıldizeli) zeolite for environmental quality," Journal of Hazardous Materials, vol. 141, no. 1, pp. 258-263, 2007.

[42] T. Luukkonen, M. Sarkkinen, K. Kemppainen, J. Rämö, and U. Lassi, "Metakaolin geopolymer characterization and application for ammonium removal from model solutions and landfill leachate," Applied Clay Science, vol. 119, pp. 266-276, 2016.

[43] Y. Zheng, Y. Liu, and A. Wang, "Fast removal of ammonium ion using a hydrogel optimized with response surface methodology," Chemical Engineering Journal, vol. 171, no. 3, pp. 1201-1208, 2011.

[44] K. Zare, H. Sadegh, R. Shahryari-ghoshekandi et al., "Equilibrium and kinetic study of ammonium ion adsorption by $\mathrm{Fe}_{3} \mathrm{O}_{4}$ nanoparticles from aqueous solutions," Journal of Molecular Liquids, vol. 213, pp. 345-350, 2016.

[45] L. Lei, X. Li, and X. Zhang, "Ammonium removal from aqueous solutions using microwave-treated natural Chinese zeolite," Separation and Purification Technology, vol. 58, no. 3, pp. 359-366, 2008.

[46] Y. S. Ho and G. McKay, "A comparison of chemisorption kinetic models applied to pollutant removal on various sorbents," Process Safety and Environmental Protection, vol. 76, no. 4, pp. 332-340, 1998.

[47] W. J. Weber and E. H. Smith, "Simulation and design models for adsorption processes," Environmental Science and Technology, vol. 21, no. 11, pp. 1040-1050, 1987.

[48] F. Mazloomi and M. Jalali, "Ammonium removal from aqueous solutions by natural Iranian zeolite in the presence of organic acids, cations and anions," Journal of Environmental Chemical Engineering, vol. 4, no. 2, pp. 1664-1673, 2016.

[49] M. Zhang, H. Zhang, D. Xu et al., "Removal of ammonium from aqueous solutions using zeolite synthesized from fly ash by a fusion method," Desalination, vol. 271, no. 1-3, pp. 111-121, 2011. 


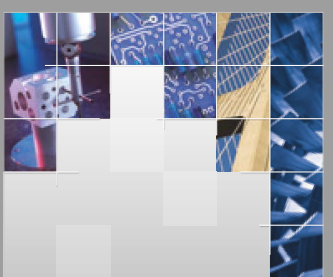

\section{Enfincering}




\section{Rotating \\ Machinery}

The Scientific World Journal

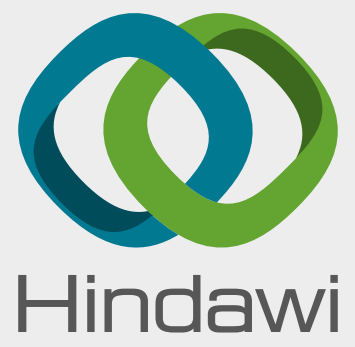

Submit your manuscripts at

www.hindawi.com
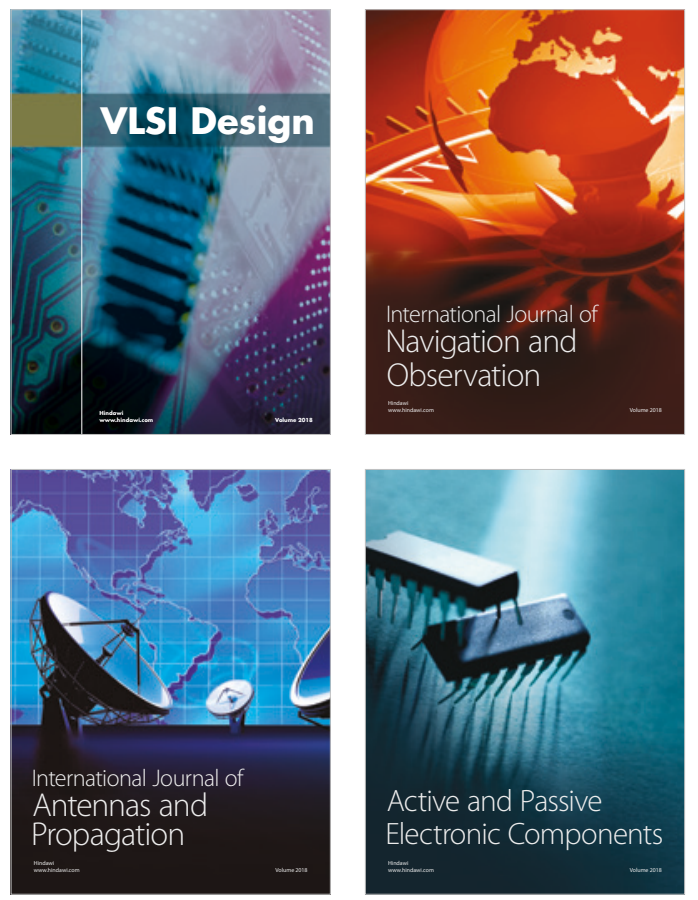
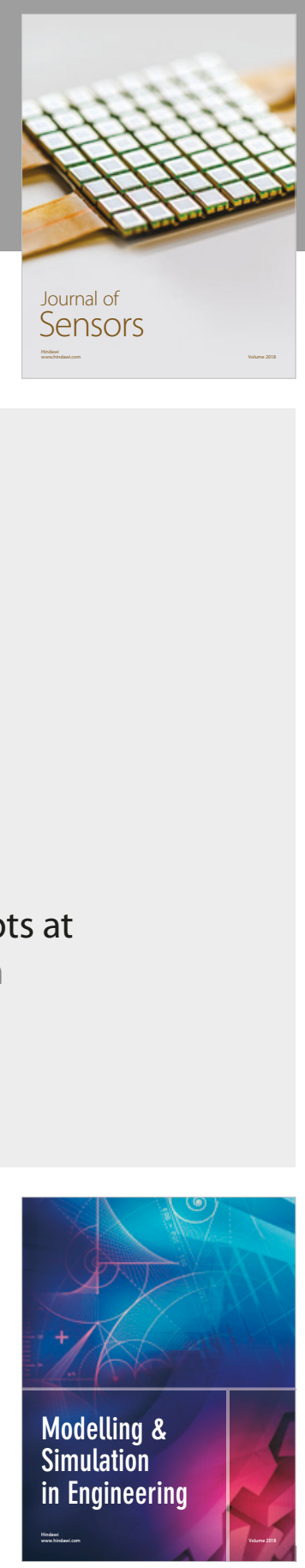

\section{Advances \\ Multimedia}
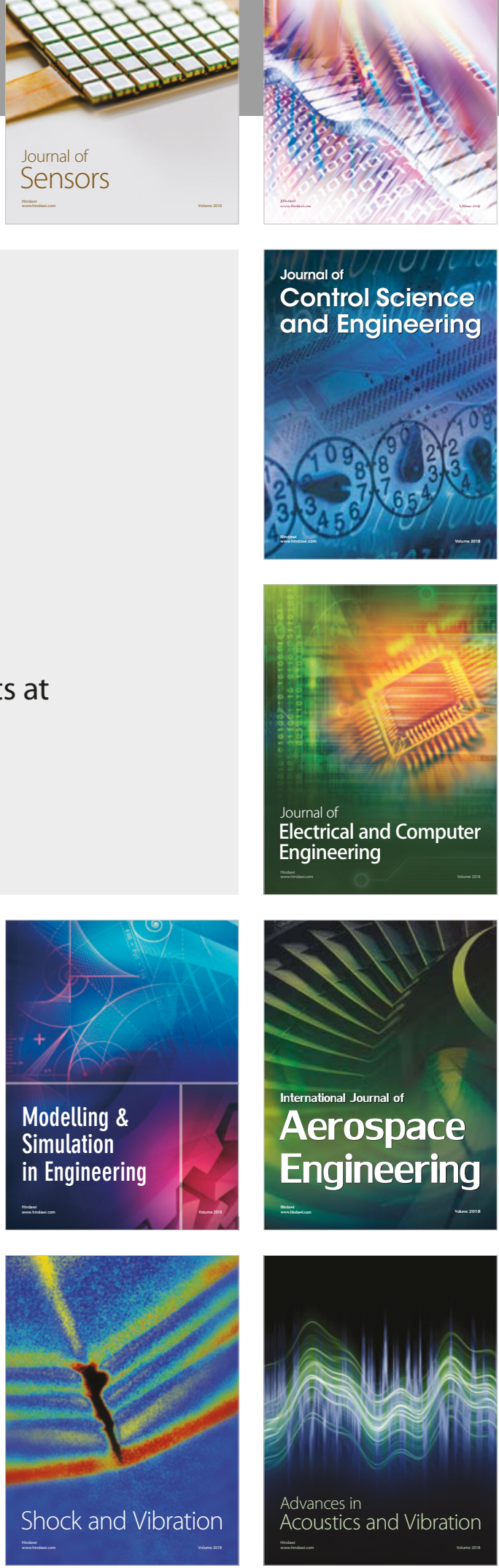